\title{
Roles, caring and learning to teach science
}

\author{
David Geelan \\ Faculty of Education, University of Queensland, Brisbane, QLD, Australia
}

Felicia Moore Mensah

Department of Mathematics, Science and Technology, Teachers College, Columbia University, P.O. Box 210, 415B Zankel Building, 525 West 120th Street, New York, NY 10027, USA

Jrene Rahm

Faculte des sciences de l'education, Departement de psychopedagogie et d'andragogie, Universite de Montreal, C.P. 6128, Succursale Centre-ville, Montreal, QC H3C 3J7, Canada

Maria Rivera Maulucci

Education Department, 336B Milbank Hall, Barnard College, 3009 Broadway, New York, NY 10027, USA

\begin{abstract}
Classroom narratives and stories are rich and powerful in offering deep insights into classrooms and the reality of teaching-a reality critically re-examined in this forum. Discussing Maria's narratives led to reflections about what it takes to support teachers to become agents of more equitable science practices. Factors such as time and identity-work are key dimensions of the authors' struggle, but they also address understanding students in profound ways. The ways in which contradictions at different levels in the educational system can become sources of growth, reflection and action are discussed; yet no simple answers follow. Teaching and becoming a teacher are best understood as life-long processes of reflection and action and as political acts that entail challenging many boundaries. They also involve putting oneself into vulnerable roles and positions. This dialogue opens up many questions about how we can collaborate, guide and support both novices and experienced professionals in education as researchers, science staff developers, and teacher educators. It seeks to support the on-going quest to make science education authentic and equitable.
\end{abstract}

David: I have been thinking and writing about the use of classroom narratives in educational research for over a decade (Geelan, 2004). Narrative methods have many features that make them powerful for understanding what happens in classrooms in ways that are rich and complex enough to approach the reality of teaching and, in the case of Maria's paper, learning to teach.

Classroom narratives and 'stories of teachers' (Clandinin and Connelly, 1996) are also very generative, particularly for those who have themselves taught in similar school classrooms. As I read Maria's account of her own teaching experiences and those of 'Tina,' the beginning teacher she was helping to develop her knowledge and skills in science teaching, a number of ideas and issues came to mind. Some are explicit or implicit in the paper, others stem more from my own reactions to the paper, the links formed between the concerns embodied in the stories that Maria tells, her analysis of those stories and my own teaching experience, tale-telling and analytical, theoretical and political commitments. 
As Maria's paper has been an occasion for reflection for those of us participating in this forum, we hope our conversation will, along with the paper, become an occasion for reflection for you, and perhaps even a spark for new professional conversations with colleagues around the teaching of science.

\section{Sinking or swimming}

David: Tina entered the classroom as part of the New York City Teaching Fellows (NYCTF) program. Like many similar programs being tried around the world, at least partly in response to a growing shortage of teachers, this program takes graduates with degrees in other fields (in Tina's case Psychology) but without any teacher education courses or qualifications and places them in schools in teaching roles. The various programs have different levels of training and support for teachers. The 5 week intensive summer course that Tina completed is fairly typical of the pre-classroom training, although some programs provide even less teacher education to beginning teachers.

Sadly, Tina's experience seems fairly typical in one other respect: these programs are designed to include large amounts of mentoring and support within the schools for the beginning teachers, in some cases including a reduced teaching load and some on-going support, but in practice little of this planned support actually materializes, and they are left to 'sink or swim.'

The New York program is also not unusual in that it places the Fellows in the most difficult-to-staff (which can also be very difficult-to-teach-in) urban schools; here beginning teachers are faced with teaching challenges that can be very daunting even to experienced professionals.

Maria's narratives indicate that Tina took a few good solid lungfuls of water in the process and half drowned, but with a bit of a helping hand from her colleagues and Maria, and after a number of situations in which she was reduced to tears, she did manage to 'swim' and succeed in her teaching. The paper, however, also mentions a number of other teachers in the program who did not.

Maria's narratives of Tina's experiences help to provide richer details and a human face to some of the complexities of teaching in urban schools, and suggest some very practical reasons why there might be problems with the effectiveness and retention of teachers in these programs.

Felicia: This allows us to bring up a very important issue regarding teaching as a profession. Do teacher candidates really know what they are getting themselves into when they say they want to be teachers? And as teacher educators, do we really know what this means in terms of preparing teachers, those who enter via traditional routes or nontraditional, alternative routes? What is immensely inherent in the idea of wanting to be a teacher is the idea of also 'becoming' a teacher and this involves time, a supportive and reflective process of coming into, learning about and being a professional. I often think that we do not emphasize this enough in our preparation and conversations about teaching; therefore, I have been doing more of this in my science 
methods courses with preservice teachers. I relay the message that teaching, as fulfilling as it is, is also a great deal of work, and that teaching science adds an additional level of challenge, especially in preparing teachers for high-poverty urban schools. The fainthearted will not be able to stand, or swim; teaching is professional work, and teachers need encouragement and support to learn and grow as professionals. They also, as Maria indicates, need to know about the emotional dimensions of becoming a teacher.

David: While evidence on these 'alternative certification' (they go by a wide range of names) teacher education programs internationally is still coming in, Darling-Hammond et al. (2005) found that teachers who entered the profession through alternative certification pathways consistently had students with lower test scores and were generally less effective than teachers who had completed teacher education programs. Guarino, Santibanez and Daley (2006) explored retention issues and found that some alternative certification programs had poorer retention rates in the profession, particularly when linked with lack of mentoring and support services, but concluded that there was as yet insufficient evidence to make a strong statement on the issue of retention.

Jre`ne: Issues of retention and of becoming a teacher are certainly also tied to questions about the timescale of such becoming, as Felicia already alluded to. The timing of the program did not allow for enough guidance and support for teachers to 're-envision' and become apprenticed into what it might mean to enact "a more caring, equitable, and agentic [way] of schooling, in general, and science education in particular" and become an expert in putting to work a social justice framework. Such is a long-term and neverending process, as Maria's reflections attest to. Tina had opportunities to play with pieces of such ways of being a teacher, yet such opportunities were continuously challenged by situational factors including being in a class with predominantly English language learners in her second year, for instance, and the many role forces teachers continuously have to contend with.

As suggested, taken together, these factors and constraints "frame the spaces of possibility" for change and the enactment of authentic caring. Tina's story also underlines well the timeline of such becoming, a slow and yet complex process well captured in the narratives in the text. Tina was continuously becoming, appropriating facets of such ways of teaching and envisioning the students, growth being occasioned often by lived contradictions that emerged as she and the students co-constructed knowledge and spaces for learning.

The point about tensions and contradictions is crucial. If we approach the situation as an activity system, tensions and contradictions are understood as opportunities for growth and change over time. For instance, Maria discusses a tension between her role as a teacher educator and coach for Tina and the time available for her to offer Tina opportunities to appropriate and act upon a social justice and caring lens to her teaching.

Another contradiction is evident in Tina's search for role models-somehow she needs someone who will offer affective guidance and local support that goes beyond what Maria can offer, even though Maria saw her role as offering such support, a role she could only enact for a short time, given the structural features of the program. These 
kinds of Roles, caring and learning to teach science contradictions, at the micro and macro level, need to be explored and unpacked. They need to be taken as points of growth for the making of new artifacts and tools for teaching and new patterns of practice, as Tina's enactment of the owl pellet unit illustrates. The case shows well that we need to appreciate teachers' practices as embedded in a complex web of "relational and contextual interactions."

Felicia: When we are trying to find a balance between extremes, we have to be alert to the shifting contexts in which we find ourselves and the particular needs we have as we shift from context to context. I think these may be the tensions and contradictions that we are talking about and the challenges both Maria and Tina had in navigating the system - the time, resources and support-that they both needed as teachers and learners.

Maria: Although policies and programs may be enacted to fast-track teachers into classrooms, including alternative certification routes, there are no short-cuts to teacher development. David, Jrene, and Felicia have all mentioned issues of time, resources, and support. Tina needed almost 2 years, and a great deal of support from colleagues and me before she could begin to assert her own teaching agenda. However, her teaching agenda was still only an approximation because it did not include an understanding of how to build upon youths' lives and experiences in meaningful ways and create a more responsive curriculum.

\section{The Lone Hero(ine)}

David: My daughter, Cassandra, is currently in her first year of studying science education. As part of an assignment she was asked to analyze a movie portrayal of a teacher. She chose 'Stand and Deliver,' the old movie starring Edward James Olmos as the heroic teacher in a tough urban school who taught the students math so inspiringly that they were accused of cheating on their calculus exam because their grades were considered implausibly good. It's a great movie, based on a true story and very inspiring. It may also, however, help to perpetuate the myth of the courageous teacher struggling to help students learn in the face of indifferent or even hostile bureaucracies and systems.

I use the term 'myth' here in its anthropological sense of a story that gives meaning, rather than to suggest that such stories are not sometimes true. The story of Jaime Escalante, on which the movie is based, is a real one, and real changes were made in the lives of his students. At the same time, is it possible that this story, and the many, many other stories, both fictional and factual, about heroic teachers that appear in books and films do not always serve the profession well? Do they underestimate the well-known and broadly acknowledged importance of collaboration in enhancing teaching? Do they enable school bureaucracies to remain indifferent or hostile, and to place the blame for outcomes on teachers who are human rather than heroic?

Felicia: Once again, this goes to the previous point of teaching as a profession. I believe that there are wonderfully gifted and caring teachers in many of the schools that educate our children. But to get noticed, do we have to produce Hollywood movies like 'Stand and Deliver' and 'Dangerous Minds' and 'Dead Poets Society' to appreciate the depth of 
care, insight and knowledge needed to teach? Do we get caught up in these images of teaching and teachers and lose sight of teachers like Tina, Randi and Maria, and the complex issues surrounding how to learn as a teacher and how to educate our children?

In Maria's paper, I was reminded of her care and dedication to be a transformative educator through her personal narrative and the time she took to work with Tina and the other teachers. As I read the narratives, I was also reminded of a comment that one of my professors made about my work in professional development with teachers. Because I too become immersed in the work of enacting transformative experiences through professional development and in my science methods courses, he said, "Felicia, how will you do all of this? You're only one person." I was not sure how to answer that question then, and I still do not have the answer; yet, like Maria, I feel the pressure of this "on-going struggle to reenvision and enact a more caring, equitable, and agentic schooling" for students and teachers, to help develop teachers who are involved in the learning and teaching of science that is powerful and meaningful not only for teachers but also for their students. So, the answer is, just do it.

David: Maria's paper richly portrays both her and Tina's struggles to support students and fulfill their social justice aspirations by offering extra opportunities to these urban students and engaging them in exciting science learning experiences. The narratives also richly show the extent to which these struggles were often against systems, bureaucracies and school administrators, and address the resistance that is required on the part of teachers who aspire to social justice and to making a difference. The importance of the professional team of teachers that supported Tina in her first yearand that she credits with the fact that she was able to survive and remain in the profession at all-is also described and illustrated richly.

I would argue, therefore, that this set of narrative accounts-along with the accompanying analysis and theoretical discussion-does a richer, better job than some other forms of educational research in its ability to portray some of the realities and complexities of reform in schools and of teaching itself, especially in terms of the amount of human capital needed to carry out visions of social justice. And who knows, it may even be possible to have school administrators and bureaucrats read this work and reflect on their own assumptions and the ways in which those assumptions can tend to block the very kinds of reforms and outcomes that they would like to see occur.

Maria: One aspect of the story that I could have developed further was my political agenda. I worked in a science professional development lab that had almost anything you could want to teach middle-level science, yet the teachers in the school and in many schools in the district had so few resources. The sixth, seventh, and eighth grade classes in the school each had a dedicated classroom with some materials and a science teacher who only taught science. However, the fifth grade classes were self-contained, their teachers had little or no training in science, and they were given no materials to teach science. They literally had nothing in their closets for science. Often teachers would come to the lab and say things like, 'If I had a Lab like this, I could teach science too.' So my political agenda was all about getting materials into classrooms and into the hands of children. To do that, I had to work directly with the teachers, but I had the blessing of the school administrators, who were happy to leave science to me. This actually gave the teachers and me tremendous freedom to push the boundaries of what science could be. 


\section{Professional judgment}

David: 'Owl pellets' is a fantastic story and just so rich in describing the beginning and evolving confidence and self-efficacy of a beginning teacher who had struggled and been quite cautious about her own professional knowledge. Tina makes a professional judgment that is not particularly popular with some of her colleagues, and stands by it, and the learning results for her students seem to bear out her decision.

And yet... was she really as ready as she thought she was? She was overturning the professional judgment made by other teachers with much more experience. And even if she was ready, was the extra convenience for her and the extra experience for the students who were in her class an appropriate balance against the frustrations felt by her colleagues on the team with whom she was meant to be collaborating? Did Tina in a sense betray a trust by deviating from a plan to which she had agreed during the planning process?

Certainly it seemed as though she did, based on the reactions of some of her colleagues - and since perception is reality in social contexts, it could be argued that she did actually betray their trust.

Was the image of the heroic teacher, discussed above, playing out in her decision to boldly forge forward alone? Or should her colleagues have been more trusting of her developing professional judgment, and more willing to applaud this clear evidence that she is beginning to be able to juggle the large number of competing demands that face teachers daily? There are no clear answers to these questions, but once again, the beauty of narrative accounts is that they place us as readers 'in the middest' of the situation, and ask us, 'What would you have done, and why, if you were Tina...or Maria...or one of the other teachers on the team?'

Felicia: We have to be careful when we ask teachers to go against the (new) grain (Cochran-Smith, 2001) or the team, and venture out on their own. Indeed this requires a certain amount of courage to act in ways that they feel are in their students' best interests, or to exert the power of their professional judgment. By exerting her professional judgment, Tina may very well have created uneasiness or tension between her and the veteran teachers, and even Maria and Randi, who see this green, new teacher exerting professional freedom as an act of resistance.

For example, the use of Turner's (2002) concept of stocks of knowledge, Bourdieu's (1986) concept of cultural, social and symbolic capital, and Sewell's (1992) concept of resources as schema and practices provides a constructive framework for assisting veteran teachers in seeing their roles in relation to new teachers. Perhaps these ideas are useful for explaining the sometimes 'resistant' veteran teachers we encounter in professional development and the necessity of having mentor teachers who see themselves not only as mentors but also as supporters of another's decision-making, and who are able to balance aesthetic|authentic caring roles.

Both veteran teachers and new teachers need sufficient opportunities to interact with one another such that what one brings, the other supports, and vice versa. For instance, 
in the case of Tina, she admitted that she had not been at the school or in teaching long enough to develop adequate capital and resources; she also stated that she took on 'preassembled roles' generated from images of her fifth grade science teacher. As a result of this, her students resisted her teaching and the roles and practices she enacted in the classroom; the administration reprimanded her, while not providing any support or mentoring.

Tina and the other new teachers within her grade level needed veteran teachers who understood their role as 'elders' to help Tina learn, to help Tina develop roles that were comfortable for her, and to discuss Tina's teaching, students and decision-making. What is needed are structures that allow for sharing across experiences of time, knowledge, capital and resources with veteran and new teachers. Even the 'highly regarded' eighth grade 'warden' could benefit from a more relaxed and caring relationship with her students, which she could learn from Tina, and Randi. Therefore, the point is that there is much to learn from one another-the veteran from the new, and the new teacher from veteran.

With a balance between aesthetic and authentic caring, all teachers within a school community may develop collegially as well as professionally from sharing and taking advantage of each other's knowledge, capital, and resources. Tina stated that it was the 'new' teachers, her 'friends,' who banded together to support each other. How much could they have grown and learned if there were veteran teachers, willing to mentor and learn from/with Tina and the newest of colleagues, toward developing a school environment that was concerned about similar things and had similar goals for teaching and learning, and saw developing friends as a positive outcome of their professional relationships?

Additionally, how much more could all of the teachers have learned if they approached their teaching and professional learning by discussing and making more explicit their roles as science teachers, i.e., role-taking, role-making, and role verification, as potentially powerful means of establishing themselves as reform-based science teachers and teaching science in more equitable ways?

Jrene: It points again to the timescale of becoming a teacher-in essence a project for life. Note also the ways in which such learning is situated within a complex system of meanings and practices. Maria was learning about new dimensions of aesthetic|authentic caring at a level different from Tina, yet they both engaged in 'changing participation in changing practice' (Lave, 1996, p. 161). The conditions changed and so did the forms of participation, continuously.

Maria: Increasingly in my work with preservice teachers I am finding that I have to prepare them to cope with ambiguity. Felicia has written about teachers' need to develop and utilize coping strategies particularly when teaching under stressful situations associated with economic, social, and institutional factors (Moore, 2007). Under mayoral control, New York City public schools have been under a constant barrage of reform and change. In 2004, I was a member of a hiring committee for a new middle school. We were interviewing a mathematics teacher. All of us thought the teacher seemed less than confident. In the interview, he told us, "I have been teaching for 3 years and in each year I have been given a new curriculum. I wish I could teach one 
of them 2 years in a row so that at least I could get good at it." No wonder classroom observations of this teacher showed that he was not fully comfortable with the material! So Felicia's point about going against the (new) grain is important, because for many new teachers the grain is just not obvious, and it may even shift and change in the course of a single year. In this context, time to develop expertise gets compressed and may not map onto teachers' actual developmental trajectories.

A compressed time-scale for teacher development adds to the emotional labor (Blackmore, 1996) of becoming a teacher, and contributes to the myth that it takes the exceptional, heroic teacher to be successful. Becoming a teacher, particularly for highpoverty urban settings, is fraught with emotions related to teacher identity and justice issues that must be managed or navigated (Chubbuck and Zembylas, 2008). New teachers must navigate conflicting sets of emotions framed by their beliefs about the role of the teacher as well as their sense of justice and how issues of power, privilege, and oppression play out in schools. Aesthetic|Authentic caring

David: The aesthetic|authentic construct (Valenzuela 1999) is a rich and powerful one that serves this paper well in terms of getting beyond (if I may be permitted) 'motherhood statements' about caring to look at what caring looks like in particular classroom contexts. Something I wondered about, and have already begun discussing with Maria, though, is whether any dichotomous construct tends to lead us to decide that one pole has a positive valence and the other is negative. And it's pretty hard to be against authenticity! In an earlier draft of the paper I felt Maria had fallen into this trap to some extent, disparaging the 'aesthetic caring' displayed by the education system, government bodies and other larger, systemic players in education and valorizing the authentic caring displayed by Tina and the other teachers in the school.

It might be more powerful, however, to recognize that it requires both a positive and a negative terminal to get an electric current flowing. The power and energy to make positive changes lies in the tension between two competing things, neither of which in itself needs to be considered bad or wrong. The wrong lies in an imbalance between elements that ought to be in balance, and I think the final version of the paper does a better job of exploring this dialectical relationship, recognizing the validity of aesthetic caring but at the same time making and substantiating the claim that in this school, for these students, it had become dominant to an unhealthy extent and a good dose of authentic caring was essential to re-establish a healthy balance.

Felicia: You are right to say that there are many of these 'dichotomies' at work in teaching, which Jrene comments on later, such as teaching/learning. Ideally, we want to create a fruitful balance in the ways we think about the aesthetic|authentic construct. For example, can we think about "programming, rules, policies, procedures, and accountability mechanisms" that have "individual and collective needs, interests, capacities, and cultures of youth and teachers," and can we accomplish this through curriculum, or through science content? Can we start to imagine how the aesthetic|authentic construct may look if we look at it in these ways?

The idea of bringing new and veteran teachers together in order to establish relationships, the collegial and professional supports mentioned earlier, are worth the time and effort toward striking a balance between aesthetic|authentic caring. However, 
as we know from our personal experiences and from Maria's narrative, administrative support is critical to establishing the kinds of classroom and school environments that are productive for both teacher development and student learning. The administration must be educated and given opportunities to learn about the expectations of teaching science and the support needed to teach science. It was great to have the team of fifth grade teachers and Maria to support Tina, and to support each other, but where were the other teachers in the school? How can administration take a leadership role in creating supportive networks across and within grade levels to support new and veteran teachers?

Jrene: The balance in the aesthetic|authentic construct is about the dialectical relationship between the two. They are not opposites and do not imply a dichotomy either but instead, their meaning is constituted by one and the other when understood from an activity theory perspective. Maria also referred to that dialectic in passing. Yet, as Felicia underlines, we tend to think in terms of dichotomies and struggle with perceiving the becoming of a teacher as a complex system that is continuously reconfigured and remade, and hence dynamic and changing. And as alluded to also by David at the beginning, the narratives are extremely rich in that they bring to the foreground the many dialectical relations among the components. They are layered with texts, issues, and controversies.

One tension I see is the manner in which Maria and Tina position themselves through the narratives and the work in which they are engaged. As emphasized by critical theory, learning and identity are inseparable in the sense that who I am has to do with what I am doing (Kincheloe, 2007). Evidently, the work Maria is doing is very different from Tina and in part explains their different positioning work as science teachers. They have different histories, different capital in terms of teaching experience, content expertise and pedagogical content knowledge.

But there is more to it. The manner in which they position themselves within the school and community is strikingly different. Maria refers to the school as "a place I call home" and describes it in affective ways. The genre changes drastically, as the author describes the same place in terms of numbers, referring to school report card data and demographics of the student body-data that actually tell us little about who the students are, the capital or funds of knowledge they bring to school and their world outside of the classroom. Awareness of some of those dimensions would possibly help shift Tina's focus from despair to hope.

A different kind of genre is invoked in the subsequent narrative that positions Tina as one of those devoted newcomers to that community who wants to make a difference yet struggles in doing so, and desperately searches to find "somebody to tell her how to teach, how to do it 'right."' My belief is that Tina may have focused too much on aesthetic caring at the cost of authentic caring.

Felicia: What you are describing as 'positioning' I see as connecting to my work on positional identity (Moore 2008). Though Tina does not speak specifically in terms of her race, ethnicity and class, these are inseparable social markers of identity that may explain why these narratives speak of the school and students in different ways. If we allow Maria and Tina to engage in dialogue about the centrality of how they are 
positioned in the school and within the larger society, and to discuss why this is important to address in the classroom and in teaching science, i.e., how positionality influences classroom interactions with students and how they teach, I believe Tina can come to appreciate the richness of the school, the students and the surrounding community, and see herself and her students in new ways. She can start to think of authentic ways to include the lives, communities and languages of the students in her science teaching more richly and substantially.

Furthermore, conversations between Maria and Tina may allow Tina (and Maria) to bring their life experiences into the classroom as well, so the students may become more connected to their students. Thus, teachers should take advantage of opportunities to include their lives and stories in the classroom as ways to connect with their students in authentic ways. I believe this is the nature of narrative inquiry, but I also believe that this is not done very often in classrooms.

Maria: I often see this tension in my work with teachers, both preservice and inservice, and have come to understand the importance of the journey metaphor for the process of becoming a teacher. At the time of the study, I had read Freire (1970), Tina had not. I could not help but look at the world through the critical lens of my experiences and my struggles as a Latina, one of eight children, who up until the age of nine lived in a housing project in the City. Tina could not help but look at the world through her experiences, growing up in a middle class suburb of the city, in a house with a garage and one sibling. As I worked with Tina, I could not view either of our experiences as deficits or privileges. Instead, I had to be open to the spaces she was willing to step into and change, and hope that change in those spaces could foster other openings that would enable Tina to engage more critically with the world and the power structures that frame educational inequity. Now, in my work with preservice teachers, I find that I have to allow them to see the journey. If I do that artfully, my own position on that journey in terms of my critical and social justice perspective does not seem so threatening. Maybe 1 day they can get there, or some other place just as good, too. I also constantly remind them how much they teach me every day about what it means to be a teacher. They see that I am becoming too. I see this tension as akin to the aesthetic|authentic caring dialectic. A social justice curriculum or agenda cannot usurp a preservice or inservice teacher's need to develop in ways that are productive and additive, rather than subtractive.

\section{Seeing the student}

Jrene: The form that the aesthetic|authentic dialectic takes in practices with a focus on caring and social justice is further shaped by the relationships amongst teachers and students. Tied to such relationship building is the skill all teachers need-to see the student. Such entails understanding the students' culture and history in respectful ways, and using such ways of knowing as a leverage point for teaching and the co-construction of knowledge and development of new possible selves in the classroom (Ladson-Billings 1994). The narratives illustrate well the change in Tina's ways of seeing, interacting, and respecting the students over time and resembles what Ayers (1993) describes as the "peeling away" of "layers of mystification":

As layers of mystification and obfuscation are peeled away, as the student becomes more fully present to the teacher, experiences and ways of thinking and 
knowing that were initially obscure become the ground on which real teaching can be constructed. (p. 25)

It comes through in the owl pellet activity as she extended the unit in response to the students' engagement and interest in the activity. Tina was able to notice and respect their excitement and work with it, building upon their interests. It became an emotionally charged activity that supported relationship building with the students. It is a glimpse at what a humanizing pedagogy may look like in practice-one that goes beyond simple application of teaching methods (see Nieto, 1994).

While interesting, it is clearly just a beginning. As many critical theorists emphasize, youth need to be understood in profound ways, which then makes possible the "moving of students from fear and despair to hope." Tina was still developing such ways of knowing. In contrast, Renee, despite good intentions, lacked an understanding of students' lifeworlds which made discipline problems dominate, challenging seriously her emergent yet also still very fragile identity as a teacher. Joe Kincheloe (2007) summarized it well:

To get from fear to hope, teachers must understand city kids in profound ways that account for the multiple identities of contemporary urban children and youth. Such insight most definitely takes into consideration the race, class, and gender aspects of urban student identity, but concurrently appreciates the complexity of and the multiple forces that shape the subjectivities of city kids. ( $p$. 15)

Despite some illustrations of interactions with the students, there is very little explicit talk about them in the paper. Who are they and who are they becoming (beyond their achievement scores in the table and a rough sketch of their diversity)? Tina appears to position her students in positive ways as she puts them in charge of their own learning by letting them discover things and investigate. Yet, she never translates such thoughts into what they may mean in terms of her own perception of the learners and also of learning and science literacy development.

Is she really moving beyond the packaged curriculum idea and does she make space to use curricular standards as a guide rather than as constraints? As Maxine Greene (1986) reminds us,

To engage with your students as persons is to affirm our own incompleteness, our consciousness of spaces still to be explored, desires still to be tapped, possibilities still to be opened and pursued... we have to find out how to open such spheres, such spaces, where a better state of things can be imagined...I would like to think that this can happen in classrooms, in corridors, in schoolyards, in the streets. (p. 29)

Tina does engage in some discounting work of her own when confronted with ELL students in one of her placements as she attempts to create a learning community of respect and possibilities with them. Tina attempts to "open such spheres" by "spending time [with her students] one-on-one."

While interesting and important, such ways of getting to know students are difficult to come by given the many demands that are already placed on teachers, as Felicia's 
comments also underline. One may also question some of the work Tina engaged in and the vision of her students that action embodied. For instance, grouping the students in terms of language skills, or by letting them "investigate" and "figure things out by themselves" are illustrative of actions she put forth to act upon her respect for youth. Yet, did she also notice what the students brought with them to the learning situation? Did she understand the kind of learning environment and activity that would have been meaningful to them? Did she provide them with enough opportunities for agency?

Pushing the point further, Gustavson (2007) argues for the transformation of classrooms into youthspaces, spaces that offer opportunities for students to blend their everyday creative practices with those privileged by the school system in ways that allow the two to support each other's development.

That argument emerged from Gustavson's exploration of the kind of learning youth spontaneously engage in outside of school in spaces not sanctioned by adults. As a teacher, he was concerned about his disengaged students. Instead of discounting them, he tried to learn from them about the many worlds that defined them and that they engaged in outside of school. He was surprised about the contradictions he discovered: students who were disengaged in school developed complex learning communities with a focus on literacy outside of school in spaces that were not controlled by adults.

Understanding youth in profound ways also entails the recognition of youths' abilities to reflect upon, experiment with and evaluate different practices of teaching and learning science. It entails respect of their questioning and redefining science in ways to make it inclusive of who they are, and the manner in which they can be engaged in challenging current boundaries of science. How would such ways of engaging, reflecting and questioning with students have changed Tina's science practice and transformed it into an authentic community of learning?

Maria's reflections attest to her respect and vision of students, but it is less clear how Maria could have supported Tina's development in learning to 'see' her students in different ways and come to treat youth culture as an asset in teaching. How do teachers, over such short periods of time, learn about who their students are in profound ways? How can such learning be supported?

Maria: At the end of one of the microscope labs, Tina brought one of her students over to me and said, 'Maria, Jenae refused to do any of her work today. She did not complete any of the activities.' I was surprised. Students rarely left the Lab without doing any of their work. This was truly unusual. I was also surprised that I had not noticed! When I asked Jenae, a petite, African American girl, why she did not do her work, she said, "I don't like science." Tina said 'Why? Look at all the cool stuff you get to do.' Jenae said, 'I'm not good at science. I failed science last year.' Tina and I were horrified. How does a fourth grader fail science? In my mind, only if science fails a fourth grader! Tina had to take the class upstairs at that point and I asked her to leave Jenae with me. I started pulling materials out of the cabinet-beakers, vinegar, and baking soda. Then, I started asking questions, 'Do you know what these are? What can we do with them? What do you think will happen?' By the end of the experiment, when her beaker was bubbling over, she was smiling. I said to her, 'You see? You are good at science. You can do all the things scientists do, ask questions, observe, predict, test, explain...' 
Seeing the student can be hard with large classes, packed agendas, and twin purposes of preparing students for the world as it is, with high-stakes tests to pass, as well as the world as it can be, with critical engagement and personal and societal transformation. Ideally, in this situation, there would have been an opportunity for Tina and me to talk about Jenae more critically-to pull from her story a more critical understanding of inequity in science and in education and how it gets perpetuated. I remember telling Tina what I did, but we did not go deep with that instance of seeing the student. Issues of time, resources, and responsibility intervened. I also would have liked to go deep with Jenae, to explore how the structures of schooling construct a world where a fourth grader can fail science. Maybe that would have helped to gird her against a future that might once again try to exclude her from science. I can only say, however, that I saw her working diligently during the next lab.

Felicia: I find Jrene's points interesting and challenging, especially in working with teachers to see the unique contributions that all students have and to incorporate them in the science classroom. Tina's inexperience in thinking about her students in humanizing ways or to create youth spaces in the science classroom may be the reason we do not gain valuable insights beyond the mention of her students in negative ways, or that we get an assessment of her teaching as 'useless' in the first year and learn how she struggled in the second year to communicate with and to get to know her students.

But being attuned to her students meant that she had to learn how to get to know her students, a missing link in her mentoring and education as a teacher. Through conversations, co-teaching and observing Randi and Maria, Tina gained some implicit lessons of how to work with her students; however, she needed more explicit instruction and mentoring on how to care for the 'neediest students' or her bilingual students (p. 15).

Tina looked at language, multiculturalism and the impact of culture in very limiting ways. For example, she was not aware of culturally responsive teaching as "using the cultural knowledge, prior experiences, frames of reference, and performance styles of ethnically diverse students to make learning encounters more relevant and effective for them" (Gay, 2000, p. 29). Multiculturalism was not about the students as individuals and collective members of the larger society or school, nor was it about connecting culture to learning and academics.

In the narrative, Tina eventually came to realize that spending time with her students on a personal basis proved to be beneficial in communicating and learning with her students. Yet, we do not know if Tina was able to think about her teaching beyond these initial views, especially after teaching the owl pellet lesson, and as the science specialist.

How can we help Tina reflect on the success of her science lessons from a multicultural viewpoint? How can Tina involve others, such as teachers, parents, and community, to assist her in science teaching in ways that are "culturally validating and affirming"? How can Tina encourage students' use of their first and second languages with everyday social, formal academic, and the technical science language in her classroom? Then, who is willingly available to help her make these connections? 
Jrene: While not having any concrete answers to these very complex questions, it makes me return to my reflection about time, but I try to also weave in the issue of space. Becoming a teacher is about life-long learning. Such learning and becoming is about experience but also reflection and action, a process that was encouraged and embedded in the co-teaching and mentoring process that was part of the Teaching Fellows Program (at least in theory).

Yet, reflection and action are tools teachers should invoke even once the 'official' training stops. They should be supported as practitioners in a community of practice to continue the pursuit of such reflective work.

Learning and becoming over time is also spatially and temporally marked. How Tina enacted her role as a teacher and positioned herself with her students had much to do with her own history and trajectory across space over time. It was not simply tied to her accumulated ways of knowing from participating in the professional teacher education program. Similarly, who the students are and what they do, as Gustavson (2007) emphasized, is tied to their engagement in learning in an array of spaces, some they carve out for themselves and those that are beyond adult supervision or sanctioned, and others that are more tightly controlled.

Travels across space and time constitute who we are and are becoming, as teachers and students, suggesting that these worlds also need to be reflected upon and questioned. For instance, if the teacher fellows have a history in science (bachelor degree or career in science), it would be interesting to know what they count as science and how such notions of science then translate into their teaching practice and travel across space and time. Are they reflecting upon meanings of science they have faced in the past? Are they trying to or able to re-envision such notions of science in ways that then translate into a social justice and caring approach to science teaching in their classrooms?

I return to the beginning of Maria's paper where she examines what a caring teacher implies and what authentic caring is. A quote used at the beginning defines good teachers as those that "can transmit a passion for learning" and "believe all children can learn." I suggest that a social justice stance to teaching is about putting these assumptions to work.

Yet, it still leaves me with many questions. Is action enough or does there need to be some critical ingredient and some serious deconstruction in terms of the politicization in science education practice (Seiler and Abraham 2009)? Would it potentially help Tina to better understand her socio-political location in her classroom, in society as a science teacher, and her students' position as well? And further, should not her students engage in the same sort of exercise of reflection and action, guided by a questioning about their socio-political location if we are to engage in transformative education?

\section{References}

Ayers, W. (1993). To teach, the journey of a teacher. New York: Teachers College Press.

Blackmore, J. (1996). Doing 'emotional labour' in the education market place: Stories from the field of women in management. Discourse, 17, 337-349. 
Bourdieu, P. (1986). The forms of capital. In J. G. Richardson (Ed.), Handbook of theory and research for the sociology of education (pp. 241-258). New York: Greenwood Press.

Chubbuck, S. M., \& Zembylas, M. (2008). The emotional ambivalence of socially just teaching: A case study of a novice urban school teacher. American Educational Research Journal, 45, 274-318.

Clandinin, J., \& Connelly, F. M. (1996). Teachers' professional knowledge landscapes: Teacher stories- stories of teachers-school stories-stories of schools. Educational Researcher, 25(3), 24-30.

Cochran-Smith, M. (2001). Learning to teach against the (new) grain. Journal of Teacher Education, 52, 3-4.

Darling-Hammond, L., Holtzman, D., Gatlin, S. J., \& Heilig, J. V. (2005). Does teacher preparation matter? Evidence about teacher certification, Teach for America, and teacher effectiveness. Education Policy Analysis Archives, 13(42), 1-48. Retrieved October 11, 2009, http://epaa.asu.edu/epa/v13n42/.

Freire, P. (1970). Pedagogy of the oppressed. New York: Continuum Publishing Company.

Gay, G. (2000). Culturally responsive teaching: Theory, research, and practice. New York, NY: Teachers College Press.

Geelan, D. R. (2004). Weaving narrative nets to capture classrooms. Dordrecht: Kluwer.

Greene, M. (1986). In search of a critical pedagogy. Harvard Educational Review, 56, 427441.

Guarino, C. M., Santibanez, L., \& Daley, G. A. (2006). Teacher recruitment and retention: A review of the recent empirical literature. Review of Educational Research, 76, 173-208.

Gustavson, L. (2007). Youth learning on their own terms. Creative practices and classroom teaching. New York: Routledge.

Kincheloe, J. L. (2007). City kids - not the kind of students you'd want to teach. In J. L. Kincheloe \& K. Hayes (Eds.), Teaching city kids: Understanding and appreciating them (pp. 3-38). New York: Peter Lang.

Ladson-Billings, G. (1994). The dreamkeepers: Successful teachers for African-American children. San Francisco: Jossey-Bass.

Lave, J. (1996). Teaching, as learning, in practice. Mind, Culture, and Activity: An International Journal, 3, 149-164. 
Moore, F. M. (2007). Teachers' coping strategies for teaching science in a "lowperforming" school district. Journal of Science Teacher Education, 18, 773-794.

Moore, F. M. (2008). Positional identity and science teacher professional development. Journal of Research in Science Teaching, 45, 684-710.

Nieto, S. (1994). Lessons from students on creating a chance to dream. Harvard Educational Review, 64, 392-426.

Seiler, G., \& Abraham, A. (2009). Hidden wor(l)ds in science class: Conscientization and politicization in science education research and practice. Cultural Studies of Science Education, April (online).

Sewell, W. H. (1992). A theory of structure: Duality, agency, and transformation. The American Journal of Sociology, 98, 1-29.

Turner, J. H. (2002). Face to face: Toward a sociological theory of interpersonal behavior. Stanford, CA: Stanford University Press.

Valenzuela, A. (1999). Subtractive schooling: U.S.-Mexican youth and the politics of caring. Albany: State University of New York. 